\title{
Environmental attitudes of Hungarian students and the prospects for environmental education
}

\author{
Zoltan Alfoldi $^{1}$ and Peter Alfoldi ${ }^{2}$ \\ ${ }^{1}$ University of Pannonia, Georgikon Faculty, Department of Plant Sciences and Biotechnology, \\ H-8360 Keszthely, 16 Deak Ferenc Street, e-mail: alfoldi.zoltan@georgikon.hu \\ ${ }^{2}$ Center of Well-being for Family and Children, 36 Bajcsy-Zsilinszky Street, Nagykata 2760, Hungary, e-mail: \\ alfpeter@gmail.com
}

\begin{abstract}
The efficiency of primary education is of fundamental importance in environmental education. The aim of this survey was to evaluate the environmental attitudes of young teenagers in Hungary, learning their preferences regarding plants and animals, their reasoning, and opinions about conservation. Therefore, a complex questionnaire containing 11 open questions and 5 closed questions were completed in 2016 for students between the age of 13 and 14 years. This age group was selected based on the curriculum suited the best to this type of investigation and the already advanced level of knowledge for the student. Printed questionnaires were provided to the student attending to primary schools personally, and they were asked to fill them in their class supervised by their teachers to minimalize external influences. There were 744 students living in 92 settlements of different sizes who have filled the questionnaires in 2017. These questionnaires were grouped according to the student' gender, settlement sizes (six categories), and type of home (detached house, apartment building, or prefabricated panel building). Here we report the first results after assessing the questionnaires. According to their preferences toward plants or animals, the great majority of the responders (91.3\%) favored animals, and there was no difference between boys and girls in this respect. The size of the settlements and the type of the students' home did not influence animal preference. These results suggest that teachers should particularly focus on plants in their biology and environmental education programs. When students were asked about their favorite plants, almost 80 percent of them gave priority to local plant species, especially flowers (73.1\%). More than threequarters (77\%) of the families of the students asked have at least one pet or domestic animal, and almost two-thirds (64.4\%) of them wish to have even more - although $71.1 \%$ of them live in apartment buildings or prefabricated panel buildings. Students meet animals most often (52.8\%) locally, and domestic mammals are those animals that the highest proportion (41.8\%) of them encounter. More than half (54\%) of the children go outdoors/make an excursion at least once in a month, but 11 percent of them have no such experiences. When asked about conservation, $77.7 \%$ of the children stated that they would save all of the living creatures, and $12.1 \%$ chose to save only the useful ones. This information may help in focusing on special areas for environmental education or developing new strategies and tools for it.
\end{abstract}

Keywords - environmental education, environmental attitudes, nature perception, wildlife preferences, cognitive abilities, information decisions, social sensibility, Outdoor Participation Report, Nature Deficit Disorder

Received: March 17, 2019

Accepted: July 11, 2019

\section{INTRODUCTION}

The human attitudes towards living creatures of our close or distant environments are influenced by numerous sociodemographic and other factors, including cultural beliefs, education, and economic considerations. The lack of knowledge about the complex ecology - characteristics and inter-relations - of different plant and animal species may lead to harmful decisions and activities that can damage or even destroy life-sustaining systems. For environmental sustainability, the development of environmental education strategies integrating the findings of the different areas of natural and social sciences, as well as ethical theories is of particular importance (Bart, 1972; Arcury, 1990; Gifford and 
Sussman, 2012). To achieve the principles and goals of sustainability, it is fundamentally needed that well-designed and effective environmental education programs, fitting well to the specialties of the particular age-groups form the essential part of the curriculum at every level of education. The precondition of preparing such effective environmental education programs is to learn precisely the background (basic knowledge, emotional attitudes, and all the possible factors affecting these, etc.). By this way, it is possible to determine those special areas, which should be prioritized, strengthened, and in which considerable results could be achieved.

According to the experiences of parents, teachers and researchers, beside formal education, informal ways of obtaining experience and knowledge in natural settings are of fundamental importance in the development of personality and also in the formation of environmental attitudes which are effective in different periods of lifetime (White and Stoecklin, 2008; Némethy, 2019). Environmental attitudes are the personal interest and sensitivity affected by, and reactions and activities motivated by serious and consistent commitments (Gifford and Sussman, 2012). This environmental attitude is formed as the interplay of several factors, such as perception, cognitive abilities, information decisions driven by rational and emotional motivations (Eilam and Trop, 2012, and it is influenced by gender (Roskaft et al., 2003), age (Bjerke et al., 1998; Prokop and Tunnicliffe, 2008), the physical and socio-economic status and environment (Walker and Kiecolt, 1995), previous experiences, the quality of education, cultural, religious and other spiritual influences, and politics (Asunta, 2003; Gifford and Sussman, 2012). As it was noted by Gifford and Sussman (2012), environmental attitudes have both conservation and utilization dimensions. Environmental attitudes often determine directly the relationship with and particular actions toward nature. Hines and co-workers published a metaanalysis in 1986 including 128 publications and summarized that they found positive but not very strong correlations between environmental attitudes and behavior, which was also supported by the results of Arcury (1990).

Strong (1998) points out that the sensitivity toward the state of our environment develops in childhood, and it is at a high level if someone lives a near-natural way of life. Kellert (1996) learned in his eco-psychological studies the increase of ecological and moral values based on previously obtained knowledge among teenagers (in the 13-17 age range). White and Stoecklin (2008) observed the advancement of social sensibility from the age of 12 . Yilmaz and co-workers (2004) found gender differences when evaluating environmental attitudes of primary school students. Ugulu et al. (2013) observed higher values for a scale of environmental attitudes for girls of the age between 13 and 17, comparing to those of boys. On the other hand, Saricam (2016) showed that, although the opinions of girls and boys about the environment did not differ, their relationship with nature appeared to be significantly different.
As Christmas et al. (2013) note concisely, "we all live in an ecosystem - nature does not just happen 'out there' ". Contact with nature has clearly numerous benefits for humans. Nature can be a source of happiness (Nisbet et al., 2009, 2011). Developing a close relationship with nature may depend on frequent and intensive experiences - especially from early childhood - in healthy natural environments (Ward Thompson et al. 2008) and walking outdoors facilitated a sense of nature relatedness (Nisbet and Zelenski, 2011). People who are more closely related to nature spend more time in natural sceneries and can develop rich cognitive and emotional relationships with them. These intensive effects are most likely to promote environmentally conscious attitudes and pro-environmental behavior (Nisbet and Zelenski, 2011). However, knowledge and concern for environmental issues do not necessarily predict pro-environmental behavior (Nisbet et al., 2009).

Modern lifestyles may erode people's connection with nature, as increasing urban population spend only (very) limited time in nature (White and Stoecklin, 2008), divesting them from outdoor practical and aesthetic experiences and the potential benefits of nature (Kellert and Wilson, 1993; Schultz, 2000). Towns and cities have only a few, or even lack green spaces, and people often avoid even nearby nature. The disconnections of people from the natural world may have adverse consequences for the well-being of both humans and the environment (Nisbet and Zelenski, 2011), as people lose the sense and feeling to be related to-and dependent from other creatures, and fail to utilize the advantages nature offers for human well-being. Avoiding contact with nature may also contribute to environmental degradation and destruction. People of all ages who do not feel related to nature are possibly unmotivated to protect it (Schultz, 2000; Nisbet and Zelenski, 2011).

Fast and significant changes in technology, economy, and, consequently, in society as the whole during the last decades have remarkable effects on the lifestyle and way of thinking especially for children and youngsters. Data of the current Outdoor Participation Report (2017) of the Outdoor Foundation shows that adults who were introduced to the outdoors as children were more likely to participate in outdoor activities during adulthood than those who were not exposed to the outdoors as children. A recent nation-wide assessment in England surveying the parents of young teenagers has shown that $88 \%$ of the children below 16 years went outdoor at least once a year, $70 \%$ of them experienced this once a week, but $12 \%$ had no such experiences (Hunt et al., 2016).

Richard Louv (2005) discusses in his influential book 'Last Child in the Woods', how children are losing some important connections to nature and place, and suggests some of the reasons behind this, including lack of time of parents and that of students, because of other competing after-school activities and the attractions of indoor alternatives, such as television and computer games.

Contact with the natural environment can also be limited for children and young people in contemporary society due to 
concerns about safety outdoors and issues of risk and liability (O'Brien and Murray, 2007). Louv coined the phrase 'Nature Deficit Disorder' to capture the negative consequences of the loss of experiences of nature, suggesting that this term "describes the human costs of alienation from nature, among them: diminished use of the senses, attention difficulties, and higher rates of emotional and physical illnesses. The disorder can be detected in individuals, families, and communities." (Louv, 2005).

Barbara Woods, evaluating the preferences toward animals (beloved or unloved) in Australia, found that dogs are the most favorite species and insects the least favorite ones. One of the most common reasons for the repudiation of insects was disgust (Woods, 2000). Leeming et al. (1997) set out parents, other family members, and personal experiences as the most decisive social influences for the development of environmental attitudes.

These findings highlight the importance of environmental education from early childhood continuously for all agegroups. Environmental education has a key role in conservation strategies because it could change human perception and attitudes effectively, increasing conservation of nature (Pontes-da-Silva et al. 2016). Capra (2007) has suggested to include teachers and students in more active practice of ecology in order to increase eco-literacy and to enhance conservation practices and to create new ways for it. Creative environmental education programs are of high significance to promote awareness and changes in human attitudes related to wildlife (Nates and Lindemann-Mathies 2015).

\section{MATERIALS AND METHODS}

For making up the questionnaire, which was employed in this investigation, first, we determined the target group (age and standard) based on the previous results of relevant studies which were completed in this field and the national curriculum for elementary schools in Hungary. On this basis, the range between 12 and 15 years of age (average year of age being 13.27) was chosen as the most suitable target group (that is, grade 7 in Hungary). The theoretical considerations of Kollmuss and Agyeman (2002) were also taken into account during the development of the evaluation method.

This survey was made during 2017 by asking the student to fill the printed questionnaires in personally - to avoid external influences - in Hungarian primary schools throughout TransDanubia. Altogether, 744 student from 93 settlements of different sizes grouped into six categories (with inhabitants $<1.000, \quad 1.000-5.000, \quad 5.000-20.000, \quad 20.000-100.000$, $100.000-1,000.000$, and $>1,000.000$; respectively) have completed the questionnaires, including 391 girls and 353 boys (gender ratio of $1.1: 1$ ). The questionnaires contained questions about basic information (gender, age, residence, and types of home) for the evaluation and 11 open and 5 closed questions about the preferences of student toward living creatures (plants versus animals), their favorite plant species, the most and less favorite animal species, their causative explanations forming the basis of their attitudes, and questions regarding conservation. Our main goal was to evaluate the environmental attitudes (positive and negative preferences) of students having already considerable knowledge about nature. Parental permissions were obtained in each case. Asking about the sources of information, we were interested in proving or denying the statement of Kahn formulated more than two decades ago, that is, whether the primary source of information about wildlife for children living in these particular environments was already television (Kahn, 1997). All the answers were binary coded, and the data matrix was statistically analyzed with the IBM SPSS 20 software package. In the first step of the analysis, the frequencies of the different answers were determined in percentage. Here we report the first results of these evaluations.

\section{RESULTS}

In Figure 1, the distribution of the six categories of the residences and that of the types of homes of the participating 744 students are shown with almost equal ratios of sexes. According to this figure, most students who live in a detached house belong to the four smallest categories of residence size. The residence category of prefabricated buildings has a significant proportion only in the three largest categories of residence size.

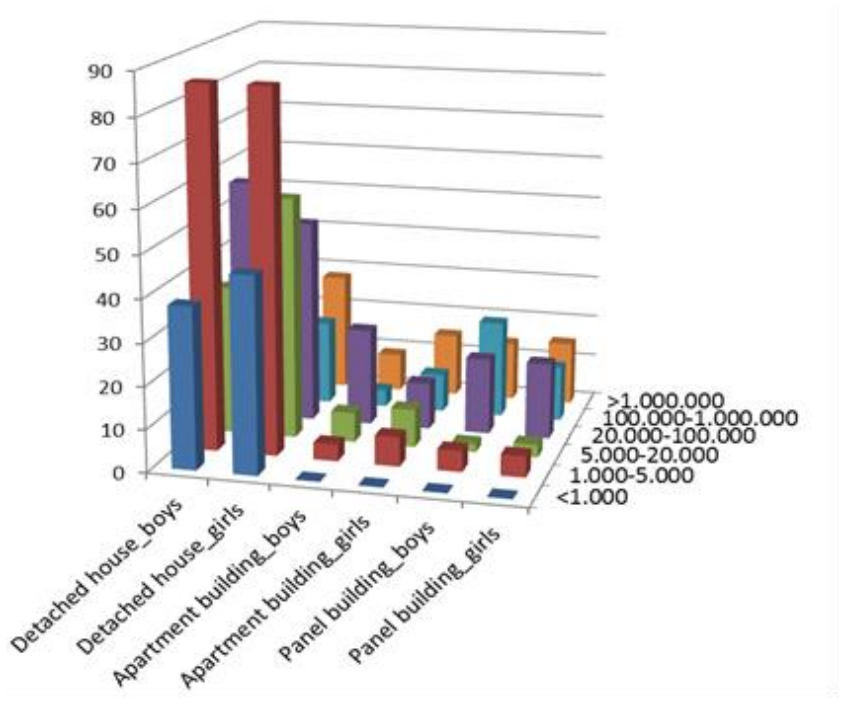

Figure 1. The distributions of the six categories of residence sizes (on the right axis) and that of the three types of homes for the two sexes (left axis) for the 744 students.

There are four or more animals in the home of almost onefifth $(19 \%)$ of the student, participated in this study, while 28,8 percent of them reported one animal, and 23 percent of them are living in families without keeping any animals. The majority $(64.4 \%)$ of the students wish to have more animals at home, and almost half $(46.7 \%)$ of them plan to have 3 animals or even more in their home during their adulthood, while 9.7 percent of them wish not to have any animal at home when grown up. Asking the student whether they prefer 
plants or animals the great majority of them $(91.3 \%$ on the average) named animals as their favorite creatures, and only 6 percent of them prefer plants to animals. The distribution of the responses according to gender, place of living expressed as six categories of settlements, and type of homes are shown in Figure 2. vegetables, or trees), with the highest proportions of domestic flowers $(73.1 \%)$.

According to the results shown in Table 2, mammals are the most favorite animals for the great majority of students $(85.5 \%)$, especially domestic mammals, for sixty percent of them. However, local wild mammals are less attractive

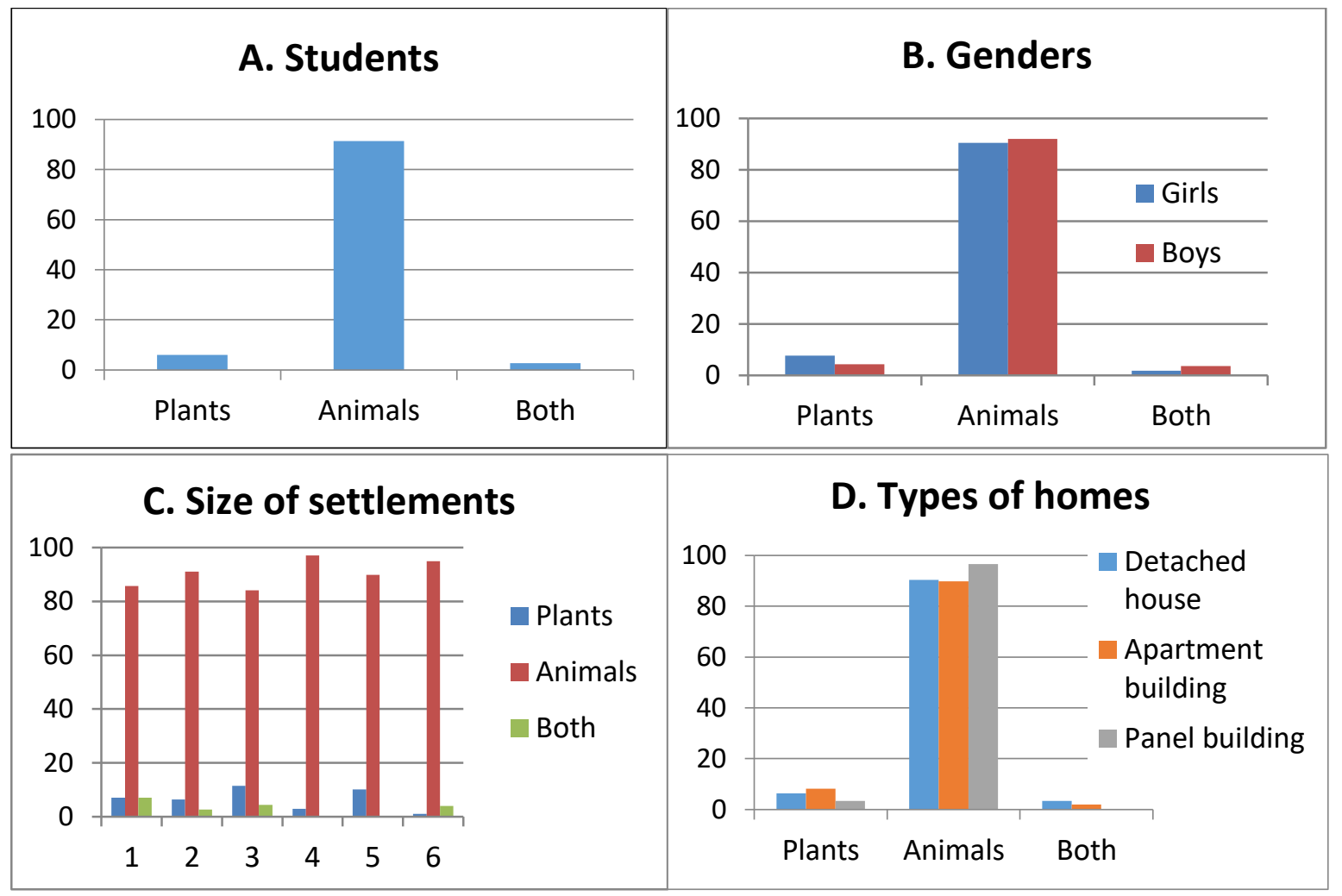

Figure 2. Distribution of the preferences for plants, animals, or both (in percentages). A. in summary of the total number of student, B. for the two sexes, C. the different categories of the sizes of residences $(1:<1.000 ; 2.1 .000-5.000 ; 3: 50.000-20.000$; 4: 20.000-100.000; 5: 100.000-1.000.000; 6: >1.000.000), and D. types of homes (detached house, apartment building, and panel building).

Table 1. The effects of back criterions (gender, size of settlements, and type of home) on the preferences - referring to Figure 2 - of the students $(\mathrm{n}=744)$, as expressed in Likelihood Ratio (LR).

\begin{tabular}{lccc}
\hline & LR value & df & P \\
\cline { 2 - 4 } Gender & 6,22 & 2 & 0.054 \\
Type of home & 10.56 & 6 & 0.103 \\
Size of settlement & 37.25 & 10 & 0,000
\end{tabular}

Preferences for animals are dominant in each case. Significant differences $(\mathrm{P}=0,001)$, as shown in Table 1 , in the magnitude for animal preference - with the same trend can only be observed for the analysis of data grouped according to the place of living. Students included in this study prefer mainly $(79.9 \%)$ domestic plants (flowers, fruits,
(3.7\%) than foreign mammals $(18.1 \%)$; and the rate of preference for pets is surprisingly low (4.3\%).

Also, the low rate of preference for birds (5.7\%) was unexpected. The highest level of antipathy was recorded for arthropods (38.2\%), but the higher value for repudiation for domestic mammals $(22.1 \%)$ than that of for reptilians $(15.6 \%)$ was also unexpected.

It was revealed that more than one-third $(37.1 \%)$ of the student know their favorite animals from their home environments. However, as an alarming fact, only a little less proportion of them (34.1\%) assigned the television and/or the internet as the source of their related information.

Personal experiences are especially necessary to develop harmonious environmental attitudes and behavior nowadays. Therefore, it is particularly noteworthy that more than onequarter $(26.4 \%)$ of the responders, according to their self- 
report, participate in an excursion only once $(15.3 \%)$, or not at all $(11.1 \%)$.

More than three-quarters $(77.7 \%)$ of the respondents would protect all the animals, while 12.1 percent of them consider only those which are useful to be worth to save. The latter responders considered probably the utilization values for these animals as their most important aspect. Almost onequarter $(24 \%)$ of those students who choose that all of the animals are worth to save accounted for their opinion with that they are living creatures (giving high priority to life), and
- providing more information about them in environmental education programs is strongly recommended. Beside school lectures, giving the chances for students to acquire practical knowledge on different plant species, including gymnosperms and angiosperms, through visiting various habitats and exhibitions, is of particular importance. Inviting practitioners such as foresters, horticulturists, agronomists, or any kind of practical gardeners could be useful in bringing students up to the wonders of the plants. Providing interesting facts and data can activate and strengthen intrinsic values and may increase the level of conscious and emotional

Table 2. Favorite and repugnant animal species and the causes of likes or dislikes for student $(\mathrm{n}=744)$.

\begin{tabular}{|c|c|c|c|c|c|c|c|}
\hline \multicolumn{2}{|l|}{ Favourites } & \multicolumn{2}{|c|}{ Reasons } & \multicolumn{2}{|l|}{ Repugnant } & \multicolumn{2}{|c|}{ Reasons } \\
\hline Categories & $\%$ & & $\%$ & & $\%$ & & $\%$ \\
\hline Domesticated mammals & 59.4 & Cute & 32.4 & Arthropods & 38.2 & Disgust & 38.1 \\
\hline Foreign mammals & 18.1 & Beautiful & 11.6 & Native mammals & 22.1 & Fear & 28.1 \\
\hline Foreign reptiles & 4.4 & Faithful & 9.6 & Reptilians & 15.6 & Ugly & 17.8 \\
\hline Pets (mammals) & 4.3 & Friendly & 9.2 & Birds & 6.3 & Harmful & 12.4 \\
\hline Native wild mammals & 3.7 & Interesting & 6.4 & Foreign mammals & 4.2 & Unfamiliarity & 3.6 \\
\hline Aquarium fishes & 2.6 & Smart & 5.8 & Amphibians & 4.0 & & \\
\hline Foreign wild birds & 2.1 & Playful & 4.6 & Molluscs & 3.6 & & \\
\hline Native wild birds & 1.6 & Useful & 4.4 & Fishes & 3.2 & & \\
\hline Cage birds & 1.2 & Big and strong & 4.0 & Worms & 2.8 & & \\
\hline Domesticated birds & 0.8 & Soft & 3.7 & & & & \\
\hline & & Fast & 2.4 & & & & \\
\hline & & Companion & 1.7 & & & & \\
\hline & & Small & 1.2 & & & & \\
\hline & & Dangerous & 1.0 & & & & \\
\hline
\end{tabular}

one-fifth $(20.1 \%)$ of them consider all of the animals as useful (for some respects); while 16.6 percent of them consider all the animals as important and necessary.

Extinction was mentioned by only 8.1 percent of the responders. The great majority of students (81.9 percent of the responders and 48.1 percent of the responses-multiple choices caused the difference in this case) identified repudiation littering as their most obvious personal act for environmental protection.

\section{CONCLUSION}

We have observed overwhelming positive preferences of Hungarian primary school student toward animals for both sexes $(91.3 \%$, on average). Based on these results, to focus on plants - especially rare and protected native plant species enthusiasm toward plants.

More than three-quarters of the students prefer different species of mammals as their favorite animals, and they assigned their preferred aesthetics ('they are cute') as the primary reason for their preference. To reveal the roles of the different classes of animals in the biosphere and also in the complex ecological systems is also essential in order to understand their significance and to improve the levels of their protection.

On the other hand, the levels of preferences for reptiles and mammals used as pets are low and equal - the latter being rather unexpected. As a high level of the negative preferences toward native mammals, more than one-fifth $(22.1 \%)$ of our respondent student consider native mammals as unfavorable for them, which is rather different from the relevant data of Ceríco (2012) asking student older than 14 years. Reptiles 
were named as their less favorite animals by 15.6 percent of the student.

In accordance with the results of Woods (2008), disgust was named as the primary reason for these rejections for 38.1 percent of the student. More than one-third (34.1\%) of the student know their favorite animals from the television, and/or via the internet, highlighting the importance of effective environmental education programs targeting young student. The incorporation of traditional ecological knowledge into the curricula also improves eco-literacy.

\section{REFERENCES}

ARCURY, T. (1990). Environmental Attitude and Environmental Knowledge. Human Organization, 49(4):300-304. https://doi.org/10.17730/humo.49.4.y6135676n433r880

ASUNTA, T. (2003). Knowledge of Environmental Issues. Where Student Acquire Information Opinions, and How it Affects their Attitudes and Laboratory Behaviour. Dissertation. Jyväskylä Studies In Education, Psychology And Social Research 221, University of Jyväskylä, Jyväskylä, Finnland.

BART, W.M. (1972). A hierarchy among attitudes toward animals. Journal of Environmental Education, 3(4):4-6.

https://doi.org/10.1080/00958964.1972.10801669

BJERKE, T., T.S. ODEGARDSTUEN, and B.P. KALTENBORN (1998). Attitudes toward animals among Norwegian children and adolescents: species preferences. Anthrozoös, 11(4), 227-235.

http://dx.doi.org/10.2752/089279398787000544

CAPRA, F. (2007). Sustainable living, ecological literacy, and the breath of life. Canadian Journal of Environmental Education, 12:9-18. https://eric.ed.gov/?id=EJ842778

CERÍACO, L.M.P. (2012). Human attitudes towards herpetofauna: The influence of folklore and negative values on the conservation of amphibians and reptiles in Portugal. J. Ethnobiology and Ethnomedicine, 8(1):8-19.

https://doi.org/10.1186/1746-4269-8-8

CHRISTMAS, S., L. WRIGHT, L. MORRIS, A. WATSON, and C. MISKELLY (2013). Engaging people in biodiversity issues: Final report of the Biodiversity Segmentation Scoping Study. Simon Christmas Ltd,

https://gybninfo.files.wordpress.com/2014/07/1998-08engaging-the-public-on-biodiversity.pdf (accessed on 24 Aug 2018)

EILAM, E. and T. TROP (2012). Environmental Attitudes and Environmental Behaviour-Which Is the Horse and Which Is the Cart? Sustainability, 4:2210-2246. https://doi.org/10.3390/su4092210

GIFFORD, R. and R. SUSSMAN (2012). The Oxford Handbook of Environmental and Conservation Psychology
(Ed.: S.D. Clayton). Oxford University Press. ISBN: 9780199733026

HINES, J.M., HUNGERFORD, H.R. and TOMERA, A.N. (1987). Analysis and synthesis of research on responsible environmental behaviour: A meta-analysis. J. Environ. Education, 18: 1-8.

https://doi.org/10.1080/00958964.1987.9943482

HUNT, A., D. STEWART, J. BURT and J. DILLON (2016). Monitor of Engagement with the Natural Environment: a pilot to develop an indicator of visits to the natural environment by children - Results from years 1 and 2 (March 2013 to February 2015). Natural England Commissioned Reports, No. 208. ISBN 978-1-78354-288-8

KAHN, P.H. (1997). Developmental psychology and the biophilia hypothesis: Children's affiliation with nature. https://doi.org/10.1006/drev.1996.0430

KELLERT, S. R. (1996). The value of life. Island Press, Washington, D.C., USA.

https://doi.org/10.1177/027046769601600415

KELLERT, S. R. (1993). The biological basis for human values of nature. In: S.R. Kellert and E. O. Wilson (Eds.), The biophilia hypothesis (pp. 42-69). Washington, D.C.: Island Press.

https://doi.org/10.1023/A:1010043827986

KOLLMUSS, A. and J. AGYEMAN (2002). Mind the Gap: why do people act environmentally and what are the barriers to pro-environmental behaviour? Environ. Education Research, 8(3):239-260. https://doi.org/10.1080/13504620220145401

LEEMING, F.C., B.E. PORTER, W. O'DWYER, M.K. COBERN and D.P. OLIVER (1997). Effects of Participation in Class Activities on Children's Environmental Attitudes and Knowledge. J. Environ. Education 28(2):33-42.

LOUV, R. (2005). Lost child in the wood. Saving our children from nature-deficit disorder. Algonquin Books.

ISBN 10-56512-522-3

NATES J. and P. LINDEMANN-MATTHIES (2015). Public knowledge and perception of, and attitudes to, frogs in Colombia. Anthrozoos 28: 319-332.

https://doi.org/10.1080/08927936.2015.11435405

NÉMETHY, S. (2019): The Balaton Ecomuseum - Touristic Product and Landscape Management in One System. Chapter in monography: Parki Narodowe i Otoczenie Społeczno Gospodarcze. Skazani na Dialog (National Parks and the Socio - economic Environment. Condemned to Dialogue) pp. 175 - 203. Wyższa Szkoła Turystyki i Ekologii w Suchej Beskidzkiej, ISBN 978-83-947044-1-4

NISBET, E.K. and J.M. ZELENSKI (2011). Underestimating Nearby Nature: Affective Forecasting Errors Obscure the 
Happy Path to Sustainability. Psychological Science, 22(9):1101-1106

https://doi.org/10.1177/0956797611418527.

NISBET, E.K., J.M. ZELENSKI, AND S.A. MURPHY (2009). The nature relatedness scale: Linking individuals' connection with nature to environmental concern and behaviour. Environment and Behaviour, 41, 715-740.

https://doi.org/10.1177/0013916508318748

NISBET, E.K., J.M. ZELENSKI, AND S.A. MURPHY (2011). Happiness is in our nature: Exploring nature relatedness as a contributor to subjective well-being. Journal of Happiness Studies, 12, 303-322.

https://doi.org/10.1007/s10902-010-9197-7

O'BRIEN, L. and MURRAY, R. (2007). Forest School and its impacts on young children: Case studies in Britain. Urban Forestry and Urban Greening, 6:249-265.

https://doi.org/10.1016/j.ufug.2007.03.006

OUTDOOR FOUNDATION (2011). Outdoor recreation. Participation Report. The Outdoor Foundation, Boulder, CO, USA. www.outdoorfoundation.org

PONTES-DA-SILVA, E., M.L.T. PACHECO, P.A.C.L. PEQUENO, E. FRANKLIN and I.L. KAEFER (2016). Attitudes towards scorpions and frogs: a survey among teachers and students from schools in the vicinity of an Amazonian protected area. J Ethnobiol 36: 395-411. http://dx.doi.org/10.2993/0278-0771-36.2.395

PROKOP, P. and S.D. TUNNICLIFFE (2008). "Disgusting" animals: primary school children's attitudes and myths of bats and spiders. Eur. J. Math. Sci. Technol. Educ. 4(2), 8797.

https://doi.org/10.12973/ejmste/75309

ROSKAFT, E., T. BJERKE, B.P. KALTENBORN, J.D.C. LINNELL, and R. ANDERSEN (2003). Patterns of selfreported fear towards large carnivores among the Norwegian public. Evolution and Human Behaviour, 24 (3), 184-198. https://doi.org/10.1016/S1090-5138(03)00011-4
SARICAM, S. (2016). Pre-adolescent concern for the natural environment according to gender. Indoor and Built Environment, 25(1):262-268. https://doi.org/10.1177/1420326X14537282

SCHULTZ, W. (2000). Empathizing with nature: The effects of perspective taking on concern for environmental issues. Journal of Social Issues, 56:391-406.

https://doi.org/10.1.1.477.4138

STRONG, C. (1998). The impact of environmental education on children's knowledge and awareness of environmental concerns. Market Intellectual Planning, 16:349-355.

UGULU, I., M. SAHIN and S. BASLAR (2013). High School Students' Environmental Attitude: Scale Development and Validation. Intl.J.Edu.Sci., 5(4):415-424.

https://doi.org/10.4236/psych.2015.613158

WALKER, G.J. and K.J. KIECOLT (1995). Social class and wilderness use. Leisure Sciences, 17:295308.https://doi.org/10.1.1.466.4211

WARD THOMPSON, C., P. ASPINALL, and A. MONTARZINO (2008). The Childhood Factor: Adult Visits to Green Places and the Significance of Childhood Experience. Environment and Behaviour, 40(1):111-143. https://doi.org/10.1177/0013916507300119

WHITE, R. and V. STOECKLIN (2008) Nurturing children's biophilia-Developmentally appropriate environmental education for young children,

http://www.whitehutchinson.com/children/articles/nurturing. shtml (accessed on 29 Aug. 2018).

WOODS, B. (2000). Beauty and the Beast: Preferences for animals in Australia. J. Tourism Studies, 11(2):25-35. https://www.jcu.edu.au/_data/assets/pdf_file/0010/123040/j cudev_012727.pdf

YILMAZ, O., W. BOONE, and H.O. ANDERSEN (2004). Views of elementary and middle school Turkish students toward environmental issues. Intl. J. Sci. Education, 26(12):1527-1546.

(C) 2019 by the authors. This article is an open-access article distributed under the terms and conditions of the Creative Commons Attribution (CC BY) license (http://creativecommons.org/licenses/by/4.0/). 